\title{
Luminal bacteria and proteases together decrease adherence of Entamoeba histolytica trophozoites to Chinese hamster ovary epithelial cells: a novel host defence against an enteric pathogen
}

\author{
E P Variyam
}

\begin{abstract}
Background-Factors that prevent colonic mucosal invasion by pathogenic Entamoeba histolytica are not understood. A key initial step in pathogenesis of injury induced by amoeba is adherence to target cells mediated by a surface glycoprotein lectin on $E$ histolytica. Mucin degrading bacteria normally present in the colon lumen produce glycosidases that degrade soluble or cell surface glycoconjugates.
\end{abstract}

Aim-To determine whether glycosidases produced by mucin degrading bacteria, alone or in combination with proteases present in colon lumen, can decrease $E$ histolytica adherence to target epithelial cells by degrading $E$ histolytica adherence lectin.

Methods-The effects of exposure of $E$ histolytica trophozoites strains HM1:IMSS and 200:NIH to faecal culture supernatant fluids, culture supernatant preparations of mucin degrading bacteria, and luminal proteases on their adherence to Chinese hamster ovary (CHO) cells were determined. The amount of surface adherence lectin on $E$ histolytica trophozoites before and after treatment with glycosidases and proteases was determined by immunofluorescence. The effect of glycosidases and proteases on purified $E$ histolytica lectin was determined by gel electrophoresis.

Results-Incubation of $E$ histolytica with culture supernatant preparations or proteases alone did not modify their $\mathrm{CHO}$ cell adherence. However, 24 hour incubation of trophozoites with culture supernatant preparations together with pancreatic proteases decreased $\mathrm{CHO}$ cell adherence of HM1:IMSS strain by $71.1 \%(p<0.001)$ and of 200:NIH strain by $95 \%(p<0 \cdot 05)$. Incubation of trophozoites for 24 hours with faecal extracts which contain bacterial and host hydrolases decreased the adherence of the HM1:IMSS strain by $69.2 \%(p<0.01)$ and of the 200:NIH strain by $83 \cdot 0 \%$. Reduction of trophozoite adherence to $\mathrm{CHO}$ cells by hydrolases was promoted by $7.5 \mathrm{mM}$ cycloheximide, and was reversible on incubation in an enzyme free medium. Decrease in CHO cell adherence of trophozoites was associated with decreased lectin on trophozoites as determined by immunofluorescence using a monoclonal antibody to the lectin.
Purified lectin was degraded by the mixture of faecal culture supernant preparations and proteases, but not by either alone.

Conclusion-Mucin degrading bacterial glycosidases and colonic luminal proteases together, but not alone, degrade the key adherence lectin on $E$ histolytica trophozoites resulting in decreased epithelial cell adherence. These in vitro findings suggest a potential novel host defence mechanism in the human colon wherein the invasiveness of a pathogen could be curtailed by the combined actions of bacterial and host hydrolases. This mechanism may be responsible for preventing mucosal invasion by pathogenic $E$ histolytica.

(Gut 1996; 39: 521-527)

Keywords: Entamoeba histolytica, intestinal amoebiasis, enteric bacteria, bacterial glycosidases, host defence mechanisms.

The enteric protozoan Entamoeba histolytica infects $10 \%$ of the world's population, resulting annually in 50 million cases of invasive amoebic diseases (colitis and liver abscess) and 100000 deaths. $^{1}$ Based on biochemical, molecular, and immunological analysis of isolates and clinical manifestations in infected people most researchers now separate $E$ histolytica into two morphologically indistinguishable varieties (species), the nonpathogenic $E$ dispar and the potentially pathogenic, true $E$ histolytica. ${ }^{2}{ }^{3}$ Other researchers still caution against separation into two species. ${ }^{45}$ It has recently become clear that most non-invasive infections are caused by $E$ dispar. ${ }^{6}$ However, even in most patients infected with true $E$ histolytica the organism does not invade colonic mucosa ${ }^{7}$ and clinical invasive diseases develop infrequently, ${ }^{8}$ although the potential for developing invasive diseases exists in everyone. ${ }^{9}{ }^{10}$ Factors which prevent tissue invasion in vivo by pathogenic $E$ histolytica are not understood.

Our knowledge of the key steps in the pathogenesis of invasive amoebiasis has advanced considerably in recent years. ${ }^{11-14}$ $E$ histolytica adheres to colonic mucus and epithelial cells mainly by a galactose $\mathrm{N}$-acetylgalactosamine inhibitable lectin, ${ }^{11-14}$ which is a major surface glycoprotein with subunits of $170 \mathrm{kDa}$ and $31-35 \mathrm{kDa} .{ }^{12}$ Lectin mediated 
adherence is a required step for target cell cytolysis. ${ }^{11-14}$ Factors capable of decreasing trophozoite lectin activity or adherence might prevent mucosal invasion by $E$ histolytica in vivo.

A subset of normal colonic anaerobic flora ('mucin degrading bacteria') produces extracellular glycosidases that degrade carbohydrate moieties of soluble and cell surface glycoconjugates. ${ }^{15-19}$ Degradation of the carbohydrate moieties enable proteases to subsequently cleave the polypeptide core of the glycosylated regions of glycoproteins. ${ }^{20}$ Thus, hydrolases normally present in the colon ecosystem-bacterial glycosidases and host and bacterial proteases-might degrade the amoebic lectin and thereby decrease adherence of $E$ histolytica to epithelial cells and prevent invasive amoebic diseases. To investigate this possibility, the effects of glycosidase containing faecal bacterial culture supernatant preparations and pancreatic proteases on the adherence of $E$ histolytica to Chinese hamster ovary $(\mathrm{CHO})$ epithelial cells were studied.

\section{Methods}

Pathogenic $E$ histolytica strains HM1:IMSS and 200:NIH (American Type Culture Collection, Rockville, MD, USA) were maintained in Diamond's TYI-S-33 medium. ${ }^{21}$ The CHO cells were maintained in minimum essential $\alpha$ medium (GIBCO Biologicals, Grand Island, New York, USA). Partially purified bacterial glycosidases were prepared from cell free supernates of early stationary phase anaerobic cultures of fresh faeces from healthy human subjects $\left(10^{-5} \mathrm{~g} / \mathrm{ml}\right.$ final concentration of inoculum) and cultures of mucin degrading bacteria isolated from human stool (Ruminococcus torques, $R$ gnavus, Bifidobacterium bifidum, and $B$ infantis) by ice cold $60 \% \mathrm{v} / \mathrm{v}$ ethanol or $3.5 \mathrm{M}$ ammonium sulphate precipitation and Sephadex G-200 gel filtration chromatography as described previously..$^{15} 16$ Faecal extracts $(20 \% \mathrm{w} / \mathrm{v})$ containing bacterial glycosidases and endogenous (host and bacterial) proteases were prepared as described previously ${ }^{16}$ by homogenisation of fresh stool, precipitation by ice cold acetone, and Sephadex G-200 gel filtration chromatography. The enzyme preparations were assayed for protein (modified Lowry method) and their major glycosidase activities (blood group $\mathrm{A}$ antigen degrading activity and paranitrophenyl $\alpha-\mathrm{N}$-acetyl galactosaminidase activity). ${ }^{16} 17$ Faecal culture supernatant preparations contain various glycosidases active against simple glycoside and complex oligosaccharide substrates, ${ }^{16-18}$ but lack protease activity against azoalbumin substrate. ${ }^{16}$ Faecal extracts contain glycosidases and protease activity. ${ }^{16}$ Trypsin, $\alpha$-chymotrypsin, and cycloheximide were purchased from Sigma Chemical Co, St Louis, MO, USA. All other chemicals were reagent grade or better. $E$ histolytica-CHO cell adherence assay was performed as described by Ravdin et al. ${ }^{12-14}$

$E$ histolytica trophozoites harvested from 48 hour cultures were washed in ice cold M-199 medium (GIBCO Biologicals, Grand Island, New York, USA) supplemented (M-199s) with $5.7 \mathrm{mM}$ cysteine, $25 \mathrm{mM}$ sodium -4 (2-hydroxyethyl) 1- piperazine ethane sulphonic acid (HEPES), $0.5 \%$ bovine serum albumin, and $1 \%(\mathrm{v} / \mathrm{v})$ antibiotic mixture (final concentration penicillin (100 units $/ \mathrm{ml})$, streptomycin $(100 \mu \mathrm{g} / \mathrm{ml})$ ) and suspended in M-199s. CHO cells, harvested by trypsinisation, were washed and suspended in ice cold M-199s. Quadruplicates of $2 \times 10^{5} \mathrm{CHO}$ cells in $12 \mathrm{~mm} \times 75 \mathrm{~mm}$ plastic tubes were mixed with $1 \times 10^{4} E$ histolytica, centrifuged at $150 \mathrm{~g}$ for three minutes, and incubated in an ice water bath. At various incubation times all but $0.1 \mathrm{ml}$ of supernatant fluid was discarded, the pellet was gently vortexed, and the suspension loaded on a haemacytometer and examined under a microscope. E histolytica trophozoites with $\geq 3$ adherent $\mathrm{CHO}$ cells were considered adherent and the percentage of adherent trophozoites determined by counting all trophozoites in the four corner chambers $(n \approx 50)$. Specificity of adherence was determined by adding $20 \mathrm{mM}$ galactose, which inhibited adherence in all studies by $>96 \%$ and in most by $100 \%$.

EFFECTS OF FAECAL CULTURE SUPERNATANT PREPARATIONS, PANCREATIC PROTEASES, AND FAECAL EXTRACTS ON E HISTOLYTICA-CHO CELL ADHERENCE

$E$ histolytica trophozoites harvested from 48 hour cultures ( $>90 \%$ viability as determined by trypan blue exclusion) were incubated in fresh TYI-S-33 medium containing $0.2 \mu \mathrm{m}$ filter sterilised faecal culture supernatant (50 $\mu \mathrm{g}-100 \mu \mathrm{g} / \mathrm{ml}$ protein), $25 \mu \mathrm{g} / \mathrm{ml}$ trypsin, and $50 \mu \mathrm{g} / \mathrm{ml} \alpha$-chymotrypsin. At these concentrations activities of the glycosidases and proteases approximated to their activities in a $2 \%-10 \%$ (w/v) faecal extract. Additionally, trophozoites were incubated in (a) TYI-S-33 medium alone, (b) medium with similar concentrations of pancreatic proteases and heat inactivated $\left(100^{\circ} \mathrm{C}\right.$ for three minutes) culture supernatant preparations ('control'), and (c) medium with culture supernatant preparations. Cultures were incubated at $35.5^{\circ} \mathrm{C}$ and gently inverted periodically. Samples were removed at various intervals, the trophozoites were harvested and counted, and their viability and adherence to $\mathrm{CHO}$ cells determined. Changes in adherence were calculated as percentage of mean adherence of control cells.

EFFECTS OF FAECAL CULTURE SUPERNATANT PREPARATIONS AND PANCREATIC PROTEASES ON E HISTOLYTICA ADHERENCE LECTIN

$E$ histolytica adherence lectin on control and enzyme treated trophozoites was detected by indirect immunofluorescence. Trophozoites washed $\times 3$ in $M-199$ s were incubated for one hour at $4^{\circ} \mathrm{C}$ with mouse monoclonal antibody to the lectin $(500 \mu \mathrm{g} / \mathrm{ml})$, washed $\times 3$ in $\mathrm{M}-199 \mathrm{~s}$, and incubated for one hour at $4^{\circ} \mathrm{C}$ with fluorescein labelled goat antimouse immuno- 
globulin $(50 \mu \mathrm{g} / \mathrm{ml})$, washed $\times 3$ in $M-199 \mathrm{~s}$, and finally washed with phosphate buffered saline. Trophozoites, untreated, and after one hour incubation at $4^{\circ} \mathrm{C}$ with either monoclonal antibody or fluorescein labelled goat antimouse immunoglobulin alone, were used as controls. Fluorescence was detected qualitatively (grades of 0 to 4+) under an immunofluorescence microscope. Paraformaldehyde fixed cells (>30000 in each) were analysed by flow cytometry in a fluorescence activated cell sorter (FACScan, Becton Dickinson).

Purified $E$ histolytica lectin $(1.4 \mu \mathrm{g} / \mu \mathrm{l})$ was mixed with an equal volume of faecal culture supernatant preparation $(50 \mu \mathrm{g} / \mathrm{ml})$ and pancreatic proteases $(50 \mu \mathrm{g} / \mathrm{ml} \alpha$-chymotrypsin, $25 \mu \mathrm{g} / \mathrm{ml}$ trypsin) and incubated for six hours at $37^{\circ} \mathrm{C}$. Controls included incubations of lectin with faecal culture supernatant preparation alone and with heat inactivated faecal culture supernatant preparation plus pancreatic proteases. Proteins from samples were separated by electrophoresis by the method of Laemmli ${ }^{22}$ on a $5 \%-15 \%$ gradient polyacrylamide gel (PAGE). Untreated lectin and a mixture of faecal culture supernatant preparation and pancreatic proteases were run in additional lanes.

\section{STATISTICAL ANALYSIS}

The $E$ histolytica-CHO cell adherence values under control and experimental conditions were compared by Student's $t$ test for unpaired data. ${ }^{23}$ Values are given as means (SEM).

\section{Results}

$E$ histolytica trophozoite counts and viability in culture were not influenced by 24 hour incubation in medium containing partially purified faecal culture supernatant preparation or pancreatic proteases. Thus trophozoite counts in medium containing faecal culture supernatant preparation were $105 \cdot 2(2 \cdot 5) \%$ of those in control medium (four experiments, $\mathrm{p}>0.1$ ) and their viabilities (trypan blue exclusion), which ranged from $92 \%$ to $98 \%$, were similar to those of trophozoites grown in control medium. Trophozoite counts in medium containing faecal culture supernatant preparation and pancreatic proteases in two experiments were $87 \cdot 5 \%$ and $91 \cdot 2 \%$ of those in control medium and their percentage viabilities were $94 \%$ and $96 \%$.

Components of the TYI-S-33 medium did not affect glycosidase activity of faecal culture supernatant preparations as determined by their ability to degrade hog gastric mucin (HGM) carbohydrates; per cent degradation of HGM carbohydrates at 24 hours and 48 hours of incubation (measured by anthrone assay, of HGM precipitable in $60 \% \mathrm{v} / \mathrm{v}$ ethanol, ${ }^{16}$ ) in TYI-S-33 medium was similar to that in standard assay buffer ( $86 \% v 94 \%$ at 24 hours, $90 \%$ v $95 \%$ at 48 hours). E histolytica trophozoites lacked blood group antigen degrading activity and glycosidase activities against various synthetic glycoside substrates, except for $\beta-\mathrm{N}$-acetylglucosaminidase. Incubation with $E$ histolytica for 48 hours and 72 hours did not change the A blood group antigen degrading activity of faecal culture supernatant preparations.

EFFECT OF FAECAL CULTURE SUPERNATES, PANCREATIC PROTEASES, AND FAECAL EXTRACTS ON EH-CHO CELL ADHERENCE The percentage of $E$ histolytica trophozoites with $\mathrm{CHO}$ cell adherence increased with time of incubation. At two hours the adherence was 68.1(0.4) for HM1:IMSS trophozoites and $42 \cdot 4(0 \cdot 5)$ for $200: \mathrm{NIH}$ trophozoites. The HM1:IMSS strain, which exhibits greater virulence in experimental animals, showed greater adherence. These results are similar to those previously published. ${ }^{14}$ Adherence was $>96 \%$ inhibitable by galactose.

Neither faecal culture supernatant preparations nor pancreatic proteases alone appreciably modified $E$ histolytica- $\mathrm{CHO}$ cell adherence when trophozoites were exposed to them for 24 hours. Incubation of $E$ histolytica trophozoites with faecal culture supernatant preparation, trypsin, and $\alpha$-chymotrypsin for periods up to seven hours did not change their adherence to $\mathrm{CHO}$ cells. Thereafter, percentage adherence rapidly decreased (Fig 1), and at 24 hours $\mathrm{CHO}$ cell adherence of the HM1:IMSS strain decreased by $71 \%$ $(p<0.001)$ and of the 200:NIH strain decreased by $95 \%(\mathrm{p}<0.05 ;$ Fig 1 and Table I) from control values ( $100 \%$ adherence). Incubation with faecal extracts, which contain

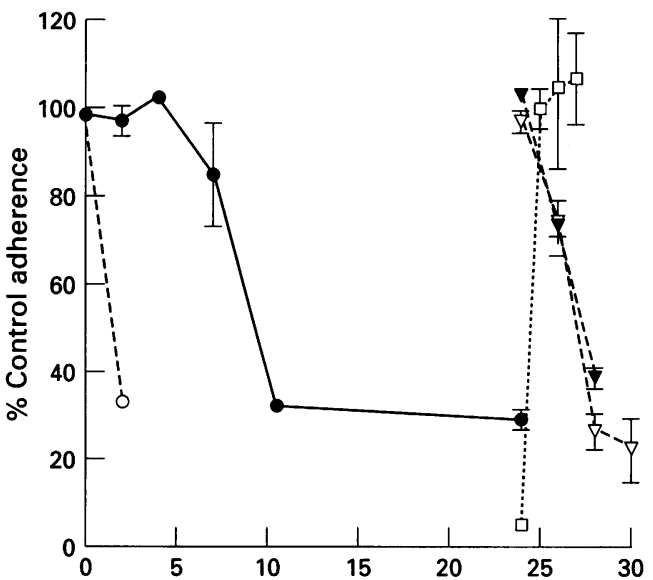

Hours of exposure of trophozoites to enzymes

Figure 1: Entamoeba histolytica (HM1:IMSS strain, except where indicated) were harvested after exposure at $35.5^{\circ} \mathrm{C}$ to hydrolase preparations as indicated and their adherence to $\mathrm{CHO}$ cells compared with that of trophozoites exposed to pancreatic proteases and heat inactivated faecal culture supernatant preparation (control). Concentration of faecal culture supernatant protein $60 \mu \mathrm{g} / \mathrm{ml}$, trypsin 25 $\mu \mathrm{g} / \mathrm{ml}, \alpha$-chymotrypsin $50 \mu \mathrm{g} / \mathrm{ml}$. Adherence is expressed as mean (SEM) of the percentage of trophozoites with rosettes. That is, $\geq 3$ adherent CHO cells at two hour incubation in an ice water bath. $=$ faecal culture supernatant preparation and pancreatic proteases; $\mathrm{O}=$ faecal culture supernatant preparation, pancreatic proteases, and cycloheximide $7.5 \mathrm{mM} ; \nabla=$ faecal culture supernate only for 24 hours, then pancreatic proteases added; $\nabla=$ pancreatic proteases only for 24 hours, than faecal culture supernatant preparation added; $\square=$ faecal culture supernatant preparation and pancreatic proteases for 24 hours, followed by wash $\times 2$ in enzyme free medium and incubated in enzyme free medium at $35 \cdot 5^{\circ} \mathrm{C}$ (200:NIH strain). 
TABLE I Mean (SEM) decrease in Entamoeba histolytica (EH) adherence to Chinese hamster ovary cells by glycosidases and proteases

\begin{tabular}{|c|c|c|c|c|}
\hline EH strain & $\begin{array}{l}\text { Before } \\
\text { exposure of EH } \\
\text { to enzymes }\end{array}$ & $\begin{array}{l}\text { After } 24 \text { h exposu } \\
\text { heat-inactivated } \\
\text { faecal cult sup } \\
\text { prep (control) }\end{array}$ & $\begin{array}{l}\text { faecal cult } \\
\text { sup prep }\end{array}$ & in, trypsin and \\
\hline HM1:IMSS & & $\begin{array}{l}67 \cdot 8(5 \cdot 3) \\
(100 \%)\end{array}$ & $\begin{array}{l}19 \cdot 6(1 \cdot 6)^{\star \star \star} \\
(28 \cdot 9 \%) \ddagger\end{array}$ & $\begin{array}{l}20 \cdot 9(5 \cdot 95)^{\star \star} \\
(30 \cdot 8 \%)\end{array}$ \\
\hline 200:NIH & $\begin{array}{l}(3) \\
38 \cdot 9(2 \cdot 8) \\
(2)\end{array}$ & $\begin{array}{l}(4) \\
40 \cdot 4(4 \cdot 1) \\
(100 \%) \\
(2)\end{array}$ & $\begin{array}{l}(4) \\
2 \cdot 0(0 \cdot 05)^{\star} \\
(5 \cdot 0 \%) \\
(2)\end{array}$ & $\begin{array}{l}(2) \\
6 \cdot 8(2 \cdot 46) \\
(17 \cdot 0 \%) \\
(1)\end{array}$ \\
\hline
\end{tabular}

$+\mathrm{EH}(\%)$ with $\geq 3$ adherent $\mathrm{CHO}$ cells at two hours.

$¥$ Compared with control adherence (\%).

Number of experiments performed, $\geq$ four replicas in each experiment.

Faecal cult sup prep $=$ faecal culture supernetent preparation.

Faecal cult sup prep $=$ faecal culture supern
${ }^{*}<00.05 ;{ }^{\star \star} p<0.01 ;{ }^{\star \star \star} \mathrm{p}<0.001 v$ control
TABLE II Decrease in Entamoeba histolytica adherence to Chinese hamster ovary cells by culture supernatant preparations from mucin degrading bacteria and pancreatic proteases *

\begin{tabular}{ll}
\hline Bacterial strain & $\begin{array}{l}\text { Decreaset in adherence } \\
(\%)(\text { mean }(S E M))\end{array}$ \\
\hline Ruminococcus torques & $35 \cdot 0(7 \cdot 1)$ \\
Ruminococcus gnavus & $82 \cdot 2(3 \cdot 5)$ \\
Bifidobacterium bifidum & $73 \cdot 4(1 \cdot 6)$ \\
Bifidobacterium infantis & $89 \cdot 8(1 \cdot 6)$ \\
\hline
\end{tabular}

^ HM1:IMSS strain trophozoites incubated for 24 hours with mucin degrading bacterial culture supernatant preparation and

pancreatic proteases.
$\dagger v$ adherence of trophozoites in enzyme free medium.

$\ddagger$ Per cent of Entamoeba histolytica with $\geq 3$ CHO cells at two hours.

glycosidases and proteases, for 24 hours decreased $\mathrm{CHO}$ cell adherence of the HM1:IMSS strain by $69.2 \%(p<0.01)$ and of the $200: \mathrm{NIH}$ strain by $83.0 \%$ (Table I).

Culture supernatant preparations of mucin degrading bacterial isolates, in combination with pancreatic proteases, also decreased $\mathrm{CHO}$ cell adherence of HM1:IMSS trophozoites (Table II). Percentage decrease in adherence from control values ranged from $35 \cdot 8 \%$ with culture supernatant preparations of $R$ torques strain IX-70 to $89 \cdot 8 \%$ with culture supernatant preparations of $B$ infantis.

Prolonged incubation (>seven hours) with faecal culture supernatant preparations and pancreatic proteases together was needed for adherence reduction (Fig 1). However, addition of $7.5 \mathrm{mM}$ cycloheximide to the incubation mixture decreased $\mathrm{CHO}$ cell adherence of HM1:IMSS trophozoites by $67 \cdot 3(0.4) \%(p<0.001)$ in two hours, shortening by fourfold the time to a comparable decrease in adherence in the absence of cycloheximide. Incubation of HM1:IMSS strain trophozoites with faecal culture supernatant preparation, pancreatic proteases, and cycloheximide was used to determine the dose relation of faecal culture supernatant preparation to adherence reduction. Decrease in adherence was proportional to the concentration of faecal culture supernatant protein (Fig 2).

Preincubation of trophozoites with either culture supernates or proteases alone also shortened the time needed to decrease $E$ histolytica-CHO adherence when the other hydrolase was added. Thus 24 hour incubation of HM1:IMSS trophozoites with faecal culture supernatant preparation alone did not modify adherence to $\mathrm{CHO}$ cells (Fig 1). When proteases were subsequently added, adherence decreased in two hours, and the decrease in adherence at four hours was similar to the decrease after >seven hours incubation of trophozoites with culture supernatant preparation and proteases. Similarly, 24 hour preincubation of trophozoites with proteases and subsequent addition of faecal culture supernatant preparation shortened the time to decrease amoeba-CHO cell adherence (Fig 1).

Decrease in $E$ histolytica trophozoite adherence to $\mathrm{CHO}$ cells by faecal culture supernatant preparation and pancreatic preteases was reversible. HM1:IMSS trophozoites that had decreased adherence after 24 hour incubation with faecal culture supernatant preparation and pancreatic proteases recovered to $99 \cdot 3(0.5) \%$ and $102 \cdot 4(1.5) \%$ of the adherence of control trophozoites at one hour and two hours respectively, of incubation in enzyme free TYI-S-33 medium. Similar results were found with 200:NIH trophozoites (Fig 1), but cycloheximide prevented full recovery: when $7.5 \mathrm{mM}$ cycloheximide was added to the medium, HM1:IMSS trophozoites failed to return to control adherence values and had only $45 \cdot 0(1 \cdot 1) \%$ of the adherence of control trophozoites at two hours.

EFFECT OF FAECAL CULTURE SUPERNATANT PREPARATIONS AND PANCREATIC PROTEASES ON E HISTOLYTICA ADHERENCE LECTIN

Before incubation of trophozoites with the enzymes the adherence lectin was detectable on the surface of most HM1:IMSS strain trophozoites with a grade $3+$ and some with lower grades. After incubation with faecal culture supernatant preparation and pancreatic proteases together the trophozoites exhibited 0 to $1+$ grade, with most having no detectable fluorescence. All other control trophozoites

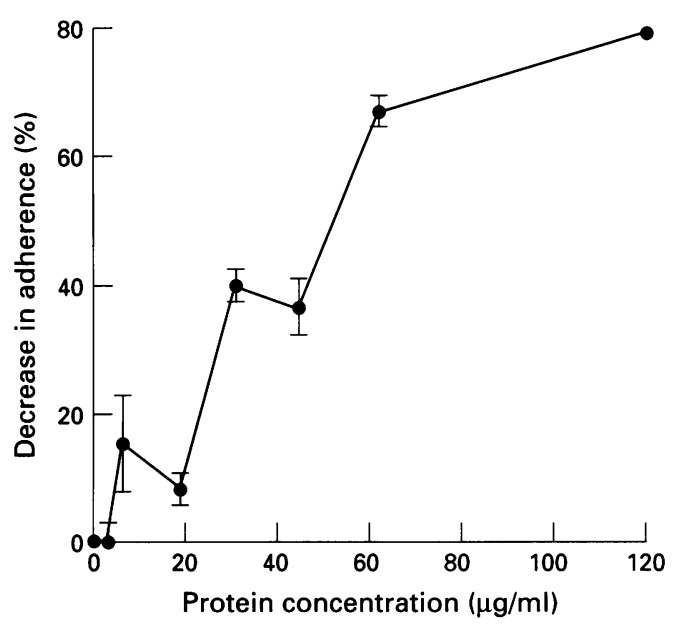

Figure 2: Entamoeba histolytica trophozoites (HM1:IMSS strain) were harvested after two hour exposure at $35 \cdot 5^{\circ} \mathrm{C}$ to faecal culture supernatant preparation, pancreatic proteases, and $7.5 \mathrm{mM}$ cycloheximide and their adherence to $\mathrm{CHO}$ cells compared with that of trophozoites exposed to pancreatic proteases and heat inactivated faecal culture supernatant preparation. Concentration of proteases used and adherence variables were similar to those in Fig 1. 
A

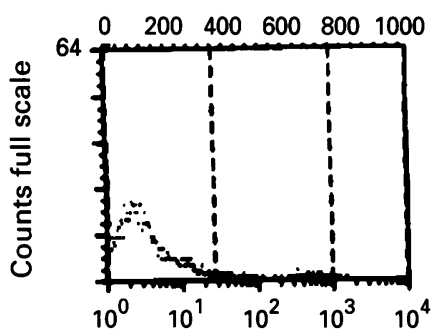

Fluorescence 1

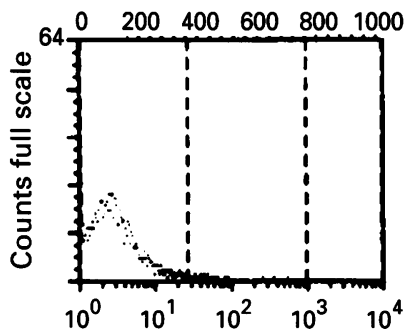

Fluorescence 1
C

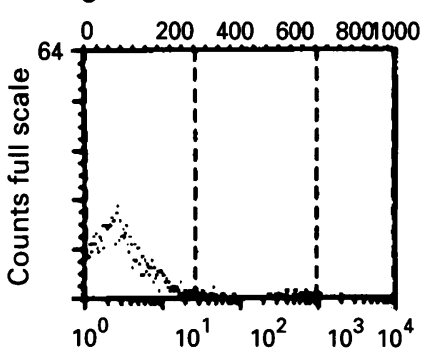

Fluorescence 1
D

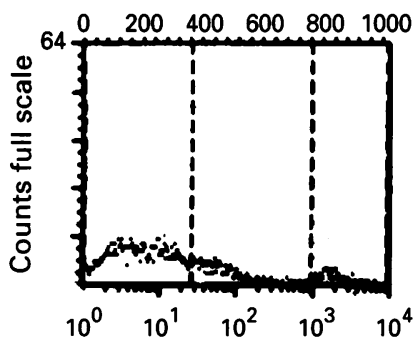

Fluorescence 1

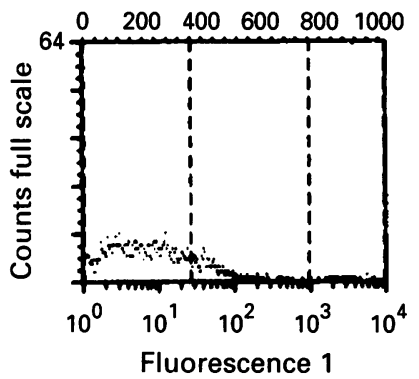

F

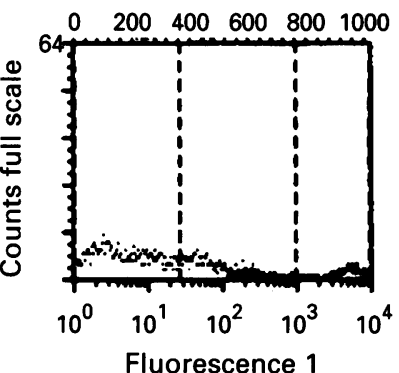

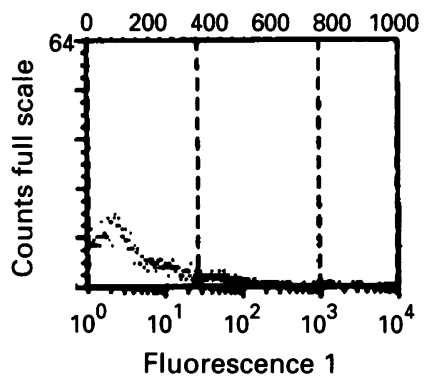

Figure 3: A-G Flow cytometry analysis of HM1:IMSS trophozoites before (control) and after incubation with faecal culture supernatant preparation and/ or pancreatic proteases and reacted with mouse antilectin monoclonal antibody and fluorescein labelled goat antimouse immunoglobulin. Cell counts (ordinate) and arbitrary fluorescence units (abscissa) in log scale. $A-D$ Control trophozoites; $A=$ reacted with neither antibody; $B=$ reacted with monoclonal antibody only; $C=$ reacted with fluorescent antibody only; $D=$ reacted with both antibodies. $E-G$ Trophozoites after incubation with enzymes and reacted with both antibodies; $E=$ incubated with faecal culture supernatant preparation only; $F=i$ incubated with pancreatic proteases only; $G=i n c u b a t e d$ with faecal culture supernatant preparation and pancreatic proteases.

TABLE III Flow cytometry analysis of Entamoeba histolytica adherence lectin *

\begin{tabular}{|c|c|c|c|c|c|}
\hline \multirow[b]{2}{*}{ Trophozoites } & \multicolumn{2}{|c|}{ Incubated with } & \multicolumn{3}{|c|}{$\begin{array}{l}\text { Cells (\%) with arbitrary } \\
\text { fluorescence units }\end{array}$} \\
\hline & $M-A b \ddagger$ & $F-A b S$ & $>30$ & $>1000$ & Total $>30$ \\
\hline \multicolumn{6}{|l|}{ Control cells: } \\
\hline Untreated & - & + & $10 \cdot 7$ & $1 \cdot 3$ & $12 \cdot 0$ \\
\hline Untreated & + & - & $5 \cdot 0$ & 0.5 & $5 \cdot 5$ \\
\hline Untreated & - & + & $7 \cdot 5$ & $1 \cdot 0$ & $8 \cdot 5$ \\
\hline Untreated & + & + & $23 \cdot 8$ & $9 \cdot 6$ & $33 \cdot 4$ \\
\hline \multicolumn{6}{|l|}{ Hydrolases treated $\dagger:$} \\
\hline Faecal cult, sup and proteases & + & + & $13 \cdot 8$ & $2 \cdot 5$ & $16 \cdot 3$ \\
\hline Faecal cult sup & + & + & $20 \cdot 5$ & $5 \cdot 0$ & $25 \cdot 5$ \\
\hline Proteases & + & + & $29 \cdot 1$ & $12 \cdot 0$ & $41 \cdot 1$ \\
\hline
\end{tabular}

*HM1:IMSS trophozoites used.

+ Concentration of hydrolases same as Table I.

$\ddagger \mathrm{M}-\mathrm{Ab}=$ mouse monoclonal antibody to lectin.

$\S \mathrm{F}-\mathrm{Ab}=$ flourescein labelled goat antimouse antibody.

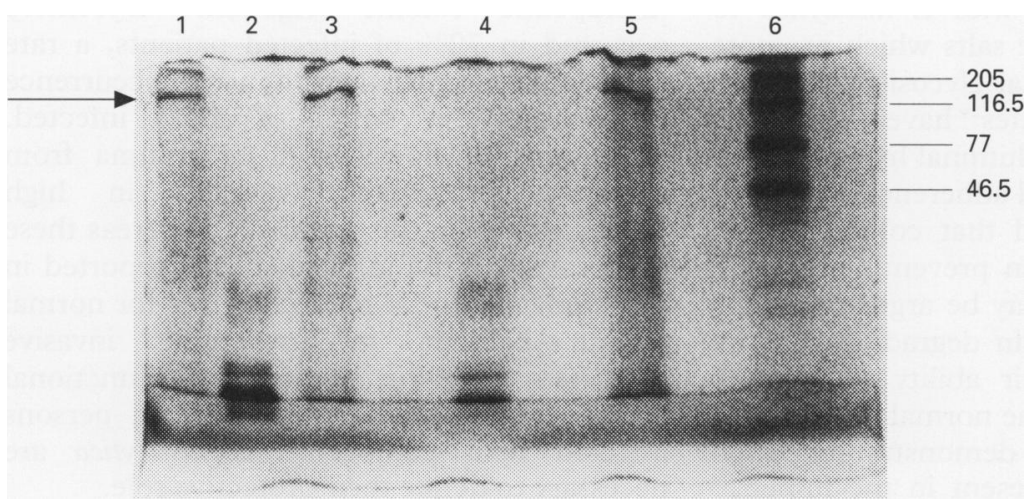

Figure 4: Polyacrylamide gel electrophoresis of $\mathrm{E}$ histolytica adherence lectin (5 $\mu \mathrm{g})$ before and after treatment with faecal culture supernatant preparation, pancreatic proteases, or both, stained with Coomassie blue. Lanes: (1) untreated lectin; (2) mixture of faecal culture supernatant preparation and pancreatic proteases with no lectin; (3) lectin treated with pancreatic proteases and heat inactivated faecal culture supernatant preparation; (4) lectin treated with faecal culture supernatant preparation and pancreatic proteases; (5) lectin treated with faecal culture supernatant preparation only; (6) molecular weight standards. Numbers in margin represent molecular mass in kDa. Arrow indicates the heavy subunit of the lectin. allowed to react with both antibodies had similar lectin levels as untreated trophozoites whereas trophozoites allowed to react with single antibody had 0 to $1+$ fluorescence. Flow cytometric analysis confirmed findings of qualitative fluorescence microscopy (Fig 3). The percentage of trophozoites with positive fluorescence (defined as $>30$ arbitrary fluorescence units) decreased by $>50 \%$ in each of three separate analysis (Table III).

Purified lectin heavy subunit was not degraded by faecal culture supernatant preparation alone or by a mixture of pancreatic proteases and heat inactivated faecal culture supernatant preparation, as determined by PAGE (Fig 4). A mixture of faecal culture supernatant preparation and pancreatic proteases degraded the heavy subunit.

\section{Discussion}

Our studies show that adherence of $E$ histolytica trophozoites to $\mathrm{CHO}$ epithelial cells is decreased by the combined effects of faecal bacterial culture supernatant preparation and endogenous (host and bacterial) luminal proteases. The levels of enzyme activities used in these studies were similar to their activities in the right colon contents in that they were $2 \%$ to $10 \%$ of their activities in a faecal extract. Adherence of $E$ histolytica to colonic epithelial cells occurs by a mechanism similar to their adherence to CHO cells. ${ }^{24}$ Therefore, it is likely that these enzyme activities would similarly decrease adherence of $E$ histolytica to colonic epithelial cells. Adherence is a key step in mucosal invasion and it is a required step for target cell cytolysis. ${ }^{11} 14$ Thus the normal 
enteric flora along with luminal proteases might prevent invasive amoebic diseases in humans by a novel host defence mechanism.

Both glycosidases and proteases were required to decrease $\mathrm{CHO}$ cell adherence of $E$ histolytica trophozoites and to degrade purified adherence lectin. This suggests that the decreased adherence might be the result of degradation of the trophozoite surface glycoprotein adherence lectin, similar to our findings on the degradation of mucin glycoproteins. ${ }^{1620}$ Alternatively, glycosidases and proteases might initially degrade glycoconjugates or proteins in the vicinity of the lectin, thereby allowing the hydrolases access to the lectin anchoring site on amoeba plasma membrane. However, faecal culture supernatant preparation did not contain detectable phospholipase-C activity (data not shown). Rapid restoration of adherence of trophozoites on removal from glycosidases and proteases suggests that decreased adherence is unlikely to be due to their effects on lectin biosynthesis or processing.

Prolonged exposure of $E$ histolytica trophozoites to faecal culture supernatant fluids and proteases was necessary to decrease their adherence to $\mathrm{CHO}$ cells. Previous studies indicate rapid turnover of $E$ histolytica plasma membrane components ${ }^{25} 26$ with a sizeable fraction of membrane components on the cell interior. Extracellular hydrolases would not be expected to degrade lectin on membrane components that are in transit in the cell interior. Cycloheximide, which inhibits protein synthesis and membrane turnover in $E$ histolytica ${ }^{25}$ shortened the period of exposure of trophozoites necessary to decrease adherence by fourfold. Rapid restoration of adherence to preincubation levels ensued when enzyme treated trophozoites were transferred to enzyme free medium; the restoration was prevented by cycloheximide. These findings are consistent with previous reports of rapid turnover of $E$ histolytica plasma membrane components. ${ }^{2526}$ In the right colon, the usual habitat of the parasite, the normal motility pattern $^{27} 28$ should allow luminal hydrolases necessary contact time with $E$ histolytica to decrease adherence. Bile salts which promote mucin degrading bacterial glycosidase activity against glycolipid substrate ${ }^{29}$ have been shown to promote the effect of luminal hydrolases on decreasing EH-CHO cell adherence. ${ }^{30}$

It has been suggested that colonic mucin plays a protective part in preventing invasive amoebic diseases. ${ }^{31}$ It may be argued that the protective effect of mucin degrading bacteria might be offset by their ability to degrade colonic mucin. But, in the normal colon a well defined mucous layer is demonstrable ${ }^{32}$ when enzyme activities are present in the lumen, ${ }^{33}$ indicating that mucin synthesis keeps up with its luminal degradation. Loss of the mucus layer, by mechanisms that may include activity of $E$ histolytica trophozoites, ${ }^{34}$ could also be a factor that promotes amoebic invasion. Luminal hydrolases may also have effects on lectin receptors on colon epithelial cells, similar to the effects of O-glycanases on such cells; $;^{35}$ such effects could modify amoeba-epithelial cell interaction.

The role of enteric bacteria in the natural history of human $E$ histolytica infection is not clear. Previous studies in vitro and in animal models have generally led to the conclusion that enteric bacteria promote colonisation and increase amoebic virulence. ${ }^{36-38}$ Such studies have generally determined the roles of facultative bacteria and have been limited in studying the role of strict anaerobes such as the mucin degrading bacteria. The studies reported here support a novel, protective role for a normal component of the strict anaerobic human colonic flora. Recent studies have shown that association of virulent axenic $E$ histolytica trophozoites with mixed bacteria leads to decreased proteolytic activity ${ }^{39}$ and to loss of carbohydate dependent $E$ histolytica surface antigen. ${ }^{40}$

Faecal populations of mucin degrading bacteria in healthy humans are generally stable. ${ }^{41}$ Occasionally, transient losses of their activities have been noted after diarrhoeal illness or antibiotic use. ${ }^{41}$ The current studies showing reduction of $E$ histolytica adherence to $\mathrm{CHO}$ epithelial cells by faecal bacterial culture supernatant preparations and endogenous proteases suggest that alterations of normal enteric flora which include a loss or decrease in activity of mucin degrading bacteria could lead to invasive amoebiasis. Indirect support for such a hypothesis is provided by two outbreaks of invasive amoebiasis, one in an airforce camp ${ }^{42}$ and another from colonic irrigation. ${ }^{43}$ Several airforce camp personnel developed amoebic dysentery after contamination of their water supply by sewage. ${ }^{42}$ Faecal prevalence of $E$ histolytica was similar among camp personnel before and after development of dysentery, indicating that the sewage contamination did not result in new cases of $E$ histolytica infection. Invasive amoebiasis occurred more often in those who developed a diarrhoeal illness before manifesting dysentery. Presumably, the diarrhoeal illness led to alterations in normal enteric flora and amoebic invasion. The second outbreak was traced to 'therapeutic' colonic irrigation. ${ }^{43}$ Dysentery occurred in $72 \%$ of infected patients, a rate considerably higher than the usual occurrence of dysentery in $<10 \%$ of those infected. Alterations of bowel flora or trauma from irrigation presumably resulted in high desentery rate in this outbreak. Whereas these outbreaks and the in vitro studies reported in this study support a protective role for normal enteric bacteria in preventing invasive amebiasis, longterm studies of the functional activities of normal enteric flora in persons infected with pathogenic $E$ histolytica are necessary to define their protective role.

This work was supported by a research grant from the US Veterans' Administration. I thank Dr Lansing C Hoskins fo providing mucin degrading bacterial isolates, Dr Jonathan Ravdin, for providing amoebic lectin and monoclonal antibody to lectin, Dr Prema Gogate for help with immunofluorescence microscopy, Dr Howard Smith for help with flow cytometry analysis, Ms Parul Shah for technical assistance, and Ms Lor Forrester for typing the manuscript. Some of these results were published in abstract form in Gastroenterology 1991;100:A622 1993;104:A796; 1996;110:A1036. 
1 Walsh JA. Problems in recognition and diagnosis of amebiasis. Estimation of global magnitude of morbidity and mortality. Reviews of Infectious Diseases 1986; 8: 228-38.

2 Diamond LS, Clark GC. A redescription of Entamoeb histolytica, Schaudin, 1903 (amended Walker, 1911) separating it from Entamoeba dispar, Brumpt, 1925. fournal of Eukaryotic Microbiology 1993; 40: 340-4.

3 Petri WA Jr, Clark GC, Diamond LS. Host-parasite relationships in amebiasis: a conference report. $f$ Infect $D$ is 1994; 169: 483-4.

4 Mirelman D, Bracha R, Rozenblatt S, Garfinkel LI Repetitive DNA elements characteristic of pathogenic Entamoeba histolytica strains can also be detected after polymerase chain reaction in a cloned nonpathogenic strain. Infect Immun 1990; 58: 1660-3.

5 Andrews BJ, Mentzoni L, Bjorvatn B. Zymodeme conversion of isolates of Entamoeba histolytica. Trans $R$ Soc Trop Med Hyg 1990; 84: 63-5.

6 Variyam EP, Gogate P, Hassan M, Costerton WJ, Pillai S, Ward $\mathrm{H}$, Jalan $\mathrm{K}$. Nondysenteric intestinal amebiasis: Colonic morphology and search for Entamoeba histolytica adherence and invasion. Dig Dis Sci 1989; 34: 732-40.

7 Gathiram V, Jackson TFHG. Frequency distribution of Entamoeba histolytica zymodemes in a rural South Africa Entamoeba histolytica zymodemes in

8 Gathiram V, Jackson TFHG. A longitudinal study of asymptomatic carriers of pathogenic zymodemes of Entamoeba histolytica. $S$ Afr Med $\mathscr{f}$ 1987; 72: 669-72.

9 World Health Organization. Amoebiasis. Report of a WHO expert committee. Geneva: WHO, 1969. (Technical report series No 421.)

10 Martinez-Palomo A. Biology of amebiasis. Progress and perspectives. In: England PT, Shera, eds. The biology of parasitism. A molecular and immunologic approach. New York: Alan R Liss (Division of J Wiley), 1988; 61-76.

11 Ravdin JI. Entamoeba histolytica: from adherence to enteropathy. F Infect Dis 1989; 159: 420-29.

12 Petri WA Jr, Smith RD, Schlesinger PH, Murphy CF Ravdin JI. Isolation of the galactose binding lectin that mediates the in vitro adherence of Entamoeba histolytica. f Clin Invest 1987; 80: 1238-44.

13 Petri WA Jr, Chapman MD, Snudgrass T, Mann BJ Broman J, Ravdin JI. Subunit structure of galactose and $\mathrm{N}$-acetyl-D-galactosamine-inhibitable lectin of Entamoeba histolytica. F Biol Chem 1989; 264: 3007-12.

14 Ravdin JI, Guerrant RL. Role of adherence in cytopathogenic mechanism of Entamoeba histolytica. Study with mammalian tissue culture cells and human erythrocytes. $¥$ Clin Invest 1981; 68: 1305-13.

15 Hoskins LC, Boulding ET. Mucin degradation in colon ecosystems. Evidence for the existence and role of bacterial subpopulations that produce glycosidases extracellular enzymes. $₹$ Clin Invest 1981 ; 67: 163-72.

16 Variyam EP, Hoskins LC. Mucin degradation in human colon ecosystems. Degradation of hog gastric mucin by fecal extracts and fecal cultures. Gastroenterology 1981, 81 $751-8$

17 Hoskins LC, Agustines M, McKee WB, Boulding ET, Kriaris $M$, Niedermeyer $G$. Mucin degradation on human colon ecosystems. Isolation and properties of fecal strains that degrade $\mathrm{ABH}$ blood group antigens and oligosaccharides for mucin glycoproteins. $\mathcal{F}$ Clin Invest 1985; 75: $944-53$.

18 Larson G, Falk P, Hoskins LC. Degradation of human intestinal glycosphingolipids by extracellular glycosidases intestinal glycosphingolipids by extracellular glycosidases from mucin-degrading bacteria of

19 Cromwell CL, Hoskins LC. In vitro degradation in human colon ecosystem. Host's ABO blood influences enteric bacterial degradation of a cell surface antigen on Escherichia coli 086. Gastroenterology 1977; 73: 37-41.

20 Variyam EP, Hoskins LC. In vitro degradation of gastric mucin. Carbohydrate side chains protect polypeptide core from pancreatic preteases. Gastroenterology 1983; 84: 533-7.

21 Diamond LS, Harlow DR, Cunnick CC. A new medium for the axenic cultivation of Entamoeba histolytica and other
Entamoebae. Trans $R$ Soc Trop Med Hyg 1978; 72: 431-2.

22 Laemmli UK. Cleavage of structural proteins during the assembly of the head of bacteria phage T4. Nature (London) 1970; 27: 680-5.

23 Hill AB. Principles of medical statistics. New York: Oxford University Press, 1961: 143-51.

24 Ravdin JI. Adherence of Entamoeba histolytica trophozoites to rat and human colonic mucosa. Infect Immun 1985; 48: 292-7.

25 Ravdin JI, Schlesinger PH, Murphy CF, Gluzman IY, Krogstad DJ. Acid intracellular vesicles and the cytolysis of mammalian target cells by Entamoeba histolytica of mammalian target cells by Entamoeba histolytica

26 Aley SB, Cohn ZA, and Scott WA. Endocytosis in Entamoeba histolytica. Evidence for a unique nonacidified compartment. $\mathcal{F}$ Exp Med 1984; 160: 724-37.

27 Christensen J. Colonic Motility. In: Schultz SG, ed Handbook of physiology. Section 6. The Gastrointestinal System. Volume I. Am Physiol Society 1989; 939-73.

28 Proano M, Camilleri M, Phillips SF, Brown ML, Thomforde GM. Transit of solids through human colon: regional quantification in the unprepared bowel. $\mathrm{Am} \mathcal{F}$ Physiol 1990; 258 (gastrointestinal and liver physiology 21): G856-62.

29 Falk P, Hoskins LC, Larson G. Enhancing effects of bile salts on the degradation of glycosphingolipids by glycosidases from bacteria of the human fecal flora. Biochem Biophys Acta 1991; 1084: 139-48.

30 Variyam EP. Bile salts promote adherence - decreasing effect of colonic luminal hydrolases on Entamoeba histolytica. Arch Med Res 1992; 23: 223-5.

31 Chadee K, Petri WA Jr, Ines DJ, Ravdin JI. Rat and human colonic mucins bind to and inhibit adherence lectin of Entamoeba histolytica. 7 Clin Invest $1987 ; 80: 1245-54$.

32 Sakata T, Engelhardt WV. Luminal mucin in the large intestine of mice, rats and guinea pigs. Cell Tissue Res 1981; 219: 629-35.

33 Prizont R, Konigsberg N. Identification of bacterial glyiosidases in rat cecal contents. Dig Dis Sci 1981; 26: glyiosid

34 Chadee K, Keller K, Forstner J, Innes DJ, Ravdin JI. Mucin and nonmucin secretagogue activity of Entamoeba histolytica and cholera toxin in rat colon. Gastroenterology 1991; 100: 986-97.

35 Campbell BJ, Finnie IA, Hounsell EF, Rhodes JM. Direct demonstration of increased expression of ThomsenFriedenreich (TF) antigen in colonic adenocarcinom and ulcerative colitis mucin and its concealment in normal mucin. $\mathcal{f}$ Clin Invest 1995; 95: 571-6.

36 Wittner M, Rosenbaum RM. Role of bacteria in modifying virulence of Entamoeba histolytica. Studies of amebas from axenic cultures. Am $\mathcal{T}$ Trop Med Hyg 1970; 19: from axen

37 Bracha R, Mirelman D. Virulence of Entamoeba histolytica rophozoites. Effects of bacteria, microaerobic condition and metronidazole. $\mathcal{F} \operatorname{Exp} M e d 1984 ; 160$ : 353-68.

38 Mirelman D. Ameba-bacterium relationship in amebiasis. Microbiol Rev 1987; 51: 272-84.

39 Spice WM, Ackers JP. The effect of axenic versus xenic culture conditions on the total and secreted proteolytic activity of Entamoeba histolytica strains. Arch Med Res 1992; 23: 91-3.

40 Bhattacharya A, Ghildyal R, Prasad J, Bhattacharya S Diamond LS. Modulation of a surface antigen of Entamoeba histolytica in response to bacteria. Infect Immun 1992; 60: 1711-3.

41 Hoskins LC. Bacterial glycosidases and degradation of glycoconjugates in the human gut. In: Wadstorm $\mathrm{T}$, ed. Molecular pathogenesis of gastrointestinal infections. New York: Plenum Press, 1991: 37-47.

42 Morton TC, Stamm WP, Seidelin R. Indigenous amoebiasis: a recent outbreak in England. BMF 1952; iii: $114-6$.

43 Istre GR, Kreiss K, Hopkins RS, Healy GR, Benziger M, Canfield TM, et al. An outbreak of amebiasis spread by colonic irrigation at a chiropractic clinic. $N$ Engl f Med 1982; 307: 339-42. 